\title{
MANUFACTURING CELL FORMATION USING SPREADSHEETS
}

\author{
Donald C. Kerr \\ Ford Motor Company of Canada, Limited \\ Oakville Ontario \\ CANADA
}

Jaydeep Balakrishnan

Finance and Operations Management Area

Faculty of Management

University of Calgary

Calgary Alberta

CANADA

Published in the International Journal of Operations and Production Management, 16, 9, 1996, 60-73. 


\title{
MANUFACTURING CELL FORMATION USING SPREADSHEETS
}

\begin{abstract}
Many algorithms have been proposed to form manufacturing cells from component routings. Most of these methods require specialized algorithms for implementation. Some others use well known procedures such as Integer Programming. However, these may be difficult for practising managers to comprehend. In this study we propose a simple method that can be implemented using spreadsheet software. The method is based on similarity coefficients and a pair-wise interchange procedure. We describe the method and the spreadsheet implementation. In addition, we also compare our procedure with many existing procedures using eight well-known problems from the literature.
\end{abstract}

The results using three evaluation measures show that the proposed procedure is effective. Given its simplicity and effectiveness, it may be useful to practitioners and researchers.

Keywords: Cellular Manufacturing Algorithms, Spreadsheets, Similarity Coefficients, Layout 


\section{MANUFACTURING CELL FORMATION USING SPREADSHEETS}

\section{$\underline{\text { INTRODUCTION }}$}

In order to be successful in today's competitive manufacturing environment, managers have had to look at new approaches. One such approach or philosophy is called Group Technology (GT). GT is based on the principle of grouping similar parts into families. This can lead to many benefits in a manufacturing facility. This paper focuses on Cellular Manufacturing (CM), an important part of GT. CM concentrates on the formation of groups of machines (cells) that process one or more part-families. Various approaches have been suggested for forming manufacturing cells. Many of them may be too complicated for practising managers to comprehend and to use. A recent survey (1), suggests that managers are interested in simple cell formation procedures. In our paper, a procedure called Spreadsheet Cell Formation Algorithm (SCFA) is developed. It forms manufacturing cells effectively, and is easy to understand and to use. It also uses software, specifically LOTUS 1-2-3, Release $3.0^{1}$ or later, that many practitioners are already familiar with, thus eliminating the learning requirements of new software.

\section{$\underline{\text { BACKGROUND }}$}

An extensive review of cell formation procedures can be found in Offodile et al. (2) and Cheng(3). A brief review of the more relevant and recent research is discussed here. Askin et al. (4) identify a Hamiltonian Path Heuristic (HPH) approach to machine grouping. They report results superior to the well known ROC2 approach of King and Nakornchai (5). Wei and Gaither (6) use a 0-1 Binary Programming (BP) approach to obtain an optimal solution. This method is

${ }^{1}$ Lotus 1-2-3 is a trademark of the Lotus Development Corporation. 
quite flexible since it can incorporate many different types of constraints. Miltenburg and Zhang (7) compare nine well-known algorithms using popular test problems from the literature and an experimental data set. Based on their results, they suggest the Ideal Seed Non-hierarchical Clustering (ISNC) algorithm of Chandrasekharan and Rajagopalan (8) as a good general approach for forming cells. In order to determine a variety of factors about group technology, Wemmerlov and Hyer (1) surveyed companies that had been using manufacturing cells . Some of their results that are relevant here are: (1) companies preferred simple techniques to form cells, (2) over one third of the companies had used formal algorithms, and, (3) many companies also did manual analyses such as modifying part routings. Other similar algorithms include the assignment model based approach of Srinivasan et al.(9), and MACE by Waghodekar and Sahu (10).

The SCFA procedure proposed here is similar to the ones described in review papers such Offodile et al. and Cheng. But it has the advantage of being visual and simple. Also, since the results are in a spreadsheet, it easily allows the decision maker to analyze the effects of rerouting or purchasing additional machines. The SCFA also provides more than one solution so that decision makers can choose from among different solutions. Given the results in (1), this procedure may be useful to practitioners.

\section{THE SCFA PROCEDURE}

\section{$\underline{\text { Determining Similarity Coefficients }}$}

Similarity coefficients (SCs) define relationships between pairs of machines or parts. The closer the relationship, the higher the SC. The SCs are determined for both parts and machines from the part-machine incidence matrix. A ' 1 ' in a part-machine incidence matrix indicates that the 
machine processes that part (see Figure 1). The SCs used here are McAuley's (11) for machines and Carrie's (12) for parts. Mosier's study (13) compared different similarity coefficients in which McAuley's SC performed quite well. McAuley's SC for machines is as follows :

$$
m_{k l}=\frac{n_{k l}}{x_{k}+y_{l}+n_{k l}}
$$

$m_{k l} \quad$ Similarity coefficient between machines $k$ and $l$

$n_{k l} \quad$ Number of parts processed on both $k$ and $l$

$x_{k} \quad$ Number of parts processed on machine $k$ but not on $l$

$y_{l} \quad$ Number of parts processed on machine $l$ but not on $k$

For example, from Figure $1, \mathrm{~m}_{13}=0.2$. An $\mathrm{m}_{\mathrm{kl}}$ is determined for all possible pairs of machines. Carrie's SC is similar to that of McAuley's except that it is for parts.

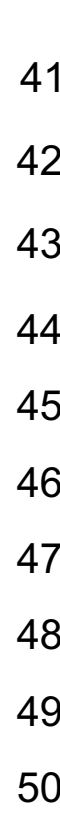

A

B

C

D E F

F G

H I

\begin{tabular}{||c||c|c|c|c|c|c|c||}
\hline \multicolumn{1}{||c||}{ Machine } & \multicolumn{7}{|c||}{ Part } \\
\hline \hline & 1 & 2 & 3 & 4 & 5 & 6 & 7 \\
\hline 1 & 1 & & & 1 & & & \\
\hline 2 & & 1 & & & & & 1 \\
\hline 3 & & & 1 & 1 & 1 & 1 & \\
\hline 4 & & 1 & & & & & 1 \\
\hline 5 & & & 1 & & 1 & 1 & \\
\hline 6 & & & 1 & & 1 & & \\
\hline 7 & 1 & & & 1 & & & \\
\hline
\end{tabular}

Figure 1

A part-machine incidence matrix 


\section{$\underline{\text { Using Similarity Coefficients in a Pair-wise Interchange Algorithm }}$}

The pair-wise interchange algorithm used here is a modification of CRAFT (Buffa et al., 14) which provides heuristic solutions for the facility layout problem. Given a set of departments, such as work areas in an office, CRAFT attempts to minimize the total cost of material handling between departments. For example, two departments that interact extensively with each other would be placed close to each other. As a result, the cost of material handling between the two departments, which depends on the travel distance and the interaction between them, would be reduced. For an extensive overview of the facility layout problem and the various algorithms available to solve it, see Kusiak and Heragu (15). CRAFT is a popular technique because it is simple and effective. If parts or machines are considered to be departments, then similarity coefficients are analogous to the material handling flow. The intention is to have machines with high similarity located near each other. Although the parts are not placed close to each other in a physical sense, those parts with high similarity should be grouped together to identify common machines. Groupings for parts and machines are solved separately. The initial sequence for the parts or machines is generated randomly. SCFA will rearrange the sequence of parts (and machines) so that similar parts (machines) are close to each other in the final sequence.

\section{Obtaining Part and Machine Sequences Using SCFA}

SCFA uses a similarity coefficient-distance (SCD) measure to determine the best sequence. For example, assume that the best sequence for a three-machine problem needs to be solved. The similarity coefficients are given in Table 1 


\begin{tabular}{||l|c|c|c||}
\hline & Machine 1 & Machine 2 & Machine 3 \\
\hline Machine 1 & 1.0 & 0.10 & 0.50 \\
\hline Machine 2 & 0.10 & 1.0 & 0.50 \\
\hline Machine 3 & 0.50 & 0.50 & 1.0 \\
\hline
\end{tabular}

Table 1

Similarity coefficients for SCFA example

\begin{tabular}{|l|l|l|}
\hline 1 & 2 & 3 \\
\hline
\end{tabular}

Figure 2

Initial layout for SCFA example

\begin{tabular}{|l|l|l|}
\hline 1 & 3 & 2 \\
\hline
\end{tabular}

Figure 3

Switched layout for SCFA example

SCFA might initially start with a layout of 1-2-3, where the distance between adjacent machines is assumed to be one (Figure 2). Thus, the distance between machines 1 and 2 is 1 . The SCD measure between machines 1 and 2 is the product of the SC and distance, i.e., $0.1 \times 1$ or 0.1 . 
Similarly, the SCD between machines 1 and 3 is $0.5 \times 2$ or 1 . The SCD between machines 2 and 3 is $0.5 \times 1$ or 0.5 . Therefore, the total SCD for this sequence is $0.1+1.0+0.5$ or 1.6 . SCFA then switches machines 3 and 2 to obtain a new sequence 1-3-2 (Figure 3). The total SCD now reduces to $0.5+0.2+0.5$ or 1.2 . Thus, the sequence $1-3-2$ is considered a better sequence. In larger problems, since many pair-wise switches are possible, all the possible pair-wise switches are evaluated based on the SCD measure and the best switch is carried out. Given 'M' machines, it requires [Mx(M-1)]/2 evaluations. The pair-wise procedure is repeated for the new sequence. SCFA terminates when no improvement is obtained by the pair-wise switches. The same procedure is repeated for the parts. The new part sequence (horizontal) and machine sequences (vertical) resulting from the pair-wise interchange procedure are used to rearrange Figure 1. This results in the final part-machine matrix in Figure 4.

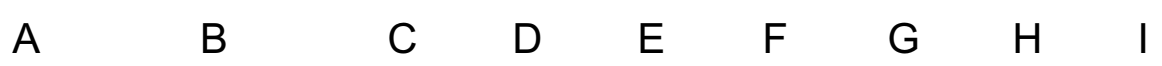

421

422

\begin{tabular}{||c||c|c|c|c|c|c|c||}
\hline \multicolumn{1}{|||||}{ Machine } & \multicolumn{7}{|c||}{ Part } \\
\hline \hline 2 & 2 & 7 & 4 & 1 & 6 & 3 & 5 \\
\hline 4 & 1 & 1 & & & & & \\
\hline 1 & & & 1 & 1 & & & \\
\hline 7 & & & 1 & 1 & & & \\
\hline 3 & & & 1 & & 1 & 1 & 1 \\
\hline 5 & & & & & 1 & 1 & 1 \\
\hline 6 & & & & & & 1 & 1 \\
\hline \hline
\end{tabular}

431 1.18

Figure 4

Final part-machine matrix showing manufacturing cells 
Machines 2 and 4 form the first cell, machines 1 and 7 form the second cell, and machines 3 , 5 and 6 form the third cell. The processing of part 4 on machine 3 is the only operation that is not assigned to a machine cell. This results in an inter-cell transfer and is called an exceptional element. Inter-cell transfers are undesirable in cellular manufacturing since they result in material handling and management complications.

\section{Visual Analysis of the Solutions}

The final sequence using SCFA is sensitive to the initial sequence. For example, if two different initial machine sequences are used, the final machine sequences could be different. To ensure a good solution, five random different initial sequences generated by SCFA for the parts and machines were used in the test problems. This gave $5 \times 5$ or 25 different final part-machine incidence matrices, some of which were identical. The best five of these based on bond energy (16) were then visually analyzed in order to determine the cells. Bond energy measures the proximity of the ' 1 's with other ' 1 's in the matrix. Since closer ' 1 's make it easier to identify cells, higher bond energies indicate better results. Figure 4 shows the cells identified in one of the five final matrices for the example problem.

\section{SPREADSHEET IMPLEMENTATION}

\section{User input screen}

Figure 5 shows the input screen. The numbers shown in bold are entered by the user. These are; the number of machines (cell B1), the number of parts (B2), the number of rows shown on the screen (B3), and the number of different random initial sequences, $N(N 1)$. The other cells in the Input Screen update the user on the status of the procedure. Cells $\mathrm{H} 1$ and $\mathrm{H} 2$ show the number of lines reserved to display the matrices for rows and parts respectively, and depend on B3. The purpose is to allow the user to page down from matrix to matrix, in this case it would page down by 20 rows. $\mathrm{J} 1$ indicates whether parts or machines are being solved currently. L1 indicates the initial sequence number being performed. L2 and N2 inform the user of the pair of machines or parts that are being exchanged; for example, in Figure 5, part 
2 is being exchanged with part 6 . N3 indicates the number of swaps that have already been carried out.

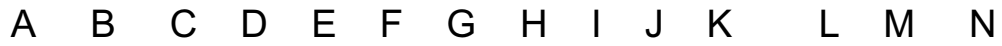
1 Mach 7 Machines windows $=20$ Part Order 1 of 5
2 Part 7 Parts windows $=20$ Swap $=>\quad 2$ with 6
3 Page $20 \quad$ Working on pass 3

Figure 5

Input Screen in Lotus 1-2-3 
Spread Sheet Computation

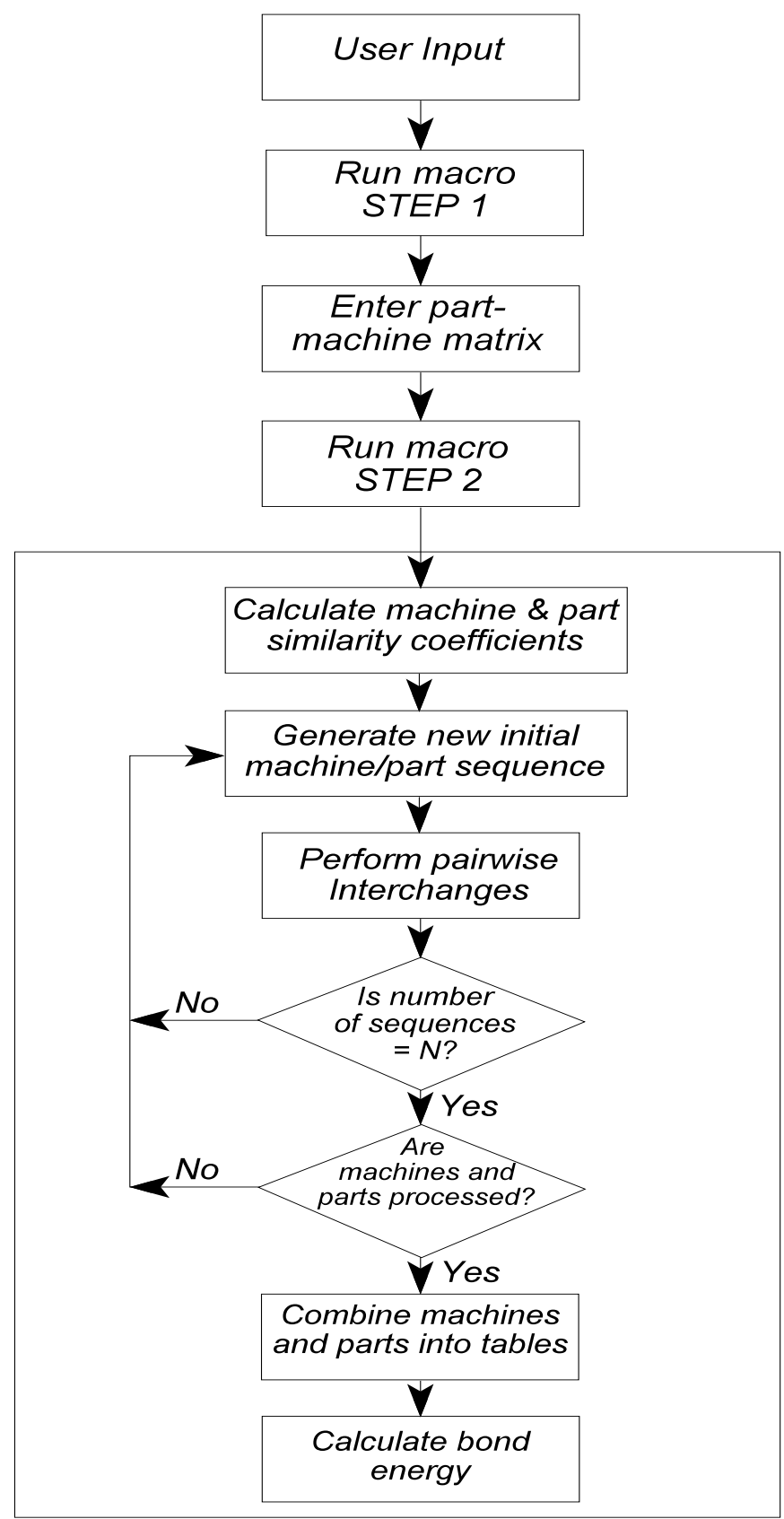

STEP 2

Figure 6

Steps in the SCFA algorithm 
Figure 6 shows the flow chart for the SCFA. The user has to enter the parameters of the problem as described above. Then, the location of macro STEP1 starting at cell P5 needs to be defined. This creates the working space of SCFA. This is done by /Range Name Create STEP1 P5. STEP1 is executed by ALT-F3 STEP1. This creates the part-machine matrix starting at row 41 as shown in Figure 1. The user has to complete the matrix by entering ' 1 's and ' 0 's. Each cell must have a ' 1 ' or a ' 0 ' for the procedure to work. STEP1 also defines ranges for other macros such as the pair-wise interchange procedures, creates formulae and writes headings.

STEP2 is then executed (ALT-F3 STEP2). STEP2 creates the machine cells as shown in Figure 4. In this case, the twenty-five machine cells start at row 421. Additional solutions can be seen by paging down. STEP2 takes the initial part-machine incidence matrix and calculates the similarity coefficients described previously. The machines are put in random order and the SCFA procedure is carried out. This is repeated as specified by the user in cell $\mathrm{N} 1$ to get the required number of final machine sequences. This analysis is carried out for parts also. The user input screen is frequently updated to inform the user of the status of the algorithm. STEP2 also creates many temporary matrices to store the intermediate calculations. The machine and part sequences are combined to form the final matrices of machine cells. At the same time the bond energy is calculated. The bond energy measure can be found just below the matrix, as shown in Figure 4. The matrices with better bond energies can be visually analysed to select alternate solutions. The LOTUS 123 SCFA code is available from the second author. 
COMPARISON WITH OTHER ALGORITHMS

Problem Set

To test the effectiveness of the SCFA procedure, eight problems from the literature were used as test problems. Table 2 shows the different problems and their characteristics. Problems 1, 3, 4, 5 and 6 were solved by Miltenburg and Zhang (7) using nine different algorithms. In these problems, the SCFA procedure results are compared to their results. In addition, problems 2, 3 and 4 were solved by Askin et al. (4) using the HPH method. They reported better results than the ROC2 algorithm. So the SCFA results from these problems are also compared to the HPH method results. Finally, problems 7 and 8 were solved optimally by Wei and Gaither (6). The optimal solutions to these two problems serve as benchmarks to evaluate the SCFA performance.

\begin{tabular}{|c|c|c|c|c|}
\hline Number & Problem & $\begin{array}{l}\text { Parts } \\
(\mathrm{N})\end{array}$ & $\begin{array}{c}\text { Machines } \\
\text { (M) }\end{array}$ & $\begin{array}{l}\text { Matrix } \\
\text { Density }\end{array}$ \\
\hline 1 & Chan \& Milner (17) & 10 & 15 & 0.31 \\
\hline 2 & De Witte (18) & 19 & 12 & 0.33 \\
\hline 3 & Chandrasekharan and Rajagopalan (8) & 20 & 8 & 0.38 \\
\hline 4 & Burbidge (19) & 43 & 16 & 0.18 \\
\hline 5 & Carrie (12) & 35 & 20 & 0.19 \\
\hline 6 & Chandrasekharan and Rajagopalan (20) & 20 & 8 & 0.57 \\
\hline 7 & Kumar and Vanelli (21) & 41 & 30 & 0.105 \\
\hline 8 & King (22) & 24 & 14 & 0.175 \\
\hline
\end{tabular}

${ }^{1}$ The matrix density is given by matrix.

$\frac{\sum_{i}^{M} \sum_{j}^{\mathrm{N}} a_{i j}}{M x N}$ where $a_{i j}=(0,1)$, one element in the part machine

Table 2

Test problem set 


\section{Performance Measures for Cell Formation Solutions}

The results are presented in the form of part-machine incidence matrices which by itself cannot convey the quality of the solution. Therefore, a method is needed to compare these matrices using evaluation measures. The three measures used by Miltenburg and Zhang (7) are used here. They are: (1) The Grouping Measure (e); (2) The Bond Energy Measure (b); and (3) The Clustering Measure (c). These measures were chosen because together they measure the within cell utilization and inter-cell movement; the ability to cluster the '1's together; and the ability to convert a random matrix into a diagonal form, respectively. Thus, they are comprehensive in their evaluation of cell formation.

\section{The Grouping Efficiency Measure}

Let $n_{1}$ denote the number of '1's in the diagonal blocks (which form the cells) in the matrix. $P_{i}$ and $Q_{i}$ represent the number of parts and machines in each cell $\mathrm{i}$ respectively. Then

$$
e_{1}=\frac{n_{1}}{\sum_{i=1}^{K} P_{i} Q_{i}}
$$

where $\mathrm{K}$ is the number of cells in the matrix and $\mathrm{e}_{1}$ is an indicator of the within cell density of a cell. Higher values of $e_{1}$ indicate greater similarity between the parts or machines in this cell. Ideally, we would want the whole cell filled with '1's. Also

$$
e_{2}=1-\frac{n_{1}}{n_{1}+n_{0}}
$$

where $n_{0}$ is the number of ' 1 's outside the cells or inter-cell transfers. Lower values of $n_{0}$ and thus lower values of $e_{2}$ indicate fewer inter-cell transfers and better solutions. The grouping efficiency, 'e' is then given by

$$
e=e_{1}-e_{2} \quad-1 \leq e \leq 1
$$


In Figure $4, e_{1}$ is $16 / 17$ or 0.941 , and $e_{2}$ is equal to $(1-(16 /(16+1)))$ or 0.059 , leading to a grouping efficiency (e) of 0.882 .

\section{The Bond Energy Measure}

When algorithms form clusters, the '1's are placed close to each other. The strength of the clustering can be computed by 'b', the normalized bond energy measure of a matrix where

$$
b=\frac{\sum_{i=1}^{M} \sum_{j=1}^{N-1} a_{i j} a_{i(j+1)}+\sum_{i=1}^{M-1} \sum_{j=1}^{N} a_{i j} a_{(i+1)}}{\sum_{i=1}^{M} \sum_{j=1}^{N} a_{i j}}
$$

The more closely linked the ' 1 's are, the higher the total bond energy measure will be and in turn the higher and better the 'b' will be. In the example in Figure 4, 'b' is 1.18. 


\section{The Clustering Measure}

Cell formation algorithms cluster '1's from a random matrix along the diagonal as shown in Figure 3 so that it becomes easier to identify the cells. In addition the further the distance of a ' 1 ' from the diagonal, the more likely it is that inter-cell travel will result. So the normalized clustering measure of a matrix, ' $c$ ' calculates the average distance of a ' 1 ' from the diagonal.

$$
c=\frac{\sum_{\text {all } a_{j}-1} \sqrt{\left(h_{a}\right)^{2}+\left(v_{a}\right)^{2}}}{\sum_{i=1}^{M} \sum_{j=1}^{N} a_{i j}} \text { where }
$$

$h_{a_{y}}$ - horizontal distance between a non-zero $a_{i j}$ and the diagonal.

$$
=i-\frac{j(M-1)}{N-1}-\frac{N-M}{N-1}
$$

$\nu_{a_{j}}$ - vertical distance between a non-zero $a_{i j}$ and the diagonal.

$$
=j-\frac{i(N-1)}{M-1}+\frac{N-M}{M-1}
$$

The closer a ' 1 ' is to the diagonal, the less is the Euclidean distance to the diagonal, and the lower and better ' $c$ ' is. In Figure 4, ' $c$ ' is 0.99 . Note that this measure is based on the north-west to south-east diagonal. If the cells are formed along a south-west to north-east diagonal for example, the rearranged matrix will have a poor clustering measure. This can be rectified by rearranging the cells along the north-west to south-east diagonal. 


\section{RESULTS}

Of the five candidate solutions resulting from the application of SCFA and the bond energy calculation, the one in which the cells could be most clearly identified was selected. Often, more than one solution had clearly identifiable cells. In these cases, two solutions were selected for comparison with the other algorithms. The results are shown in Table 3 where the SCFA is compared to the SC-Seed of Miltenburg and Zhang (7), the HPH method (4), and 0-1 Programming (6). Not all of the four procedures solved all eight problems. In the Miltenburg and Zhang study (7), with respect to the five problems included here, the SC-Seed performed best. The actual cells formed are shown in Appendix 1. The results show that SCFA performed quite well. In addition, by generating multiple solutions, the decision maker is presented with different solutions, some of which may be better than others under different situations.

The SCFA performed well even when compared to the 0-1 Programming algorithm of Wei and Gaither . The comparison was made between the unconstrained versions of Wei and Gaither and SCFA. However, 0-1 Programming is more flexible than SCFA because different types of constraints can be incorporated.

\section{CONCLUSION}

The tests conducted indicate that the SCFA procedure is an effective one regardless of matrix density. In seven out of the eight problems, it performed well on the grouping measure. This good performance is a result of the SCFA performing extremely well on the two other measures in all the problems. These two measures indicate the ability of an algorithm to rearrange random part-machine incidence matrices such that it becomes easy to identify cells. As reported in (1), many companies performed manual analyses. The ability to form diagonal matrices will ensure that a decision maker has good solutions to perform the manual analysis needed to create cells that suit the particular environment. The manual analysis may include factors such as the capacity of the machines and the capabilities of the employees. In addition, since multiple solutions are generated, the decision maker now has the flexibility of choosing 
from many solutions so that the best solution for a particular situation can be selected. For example, as seen in Table 3, the three-cell solution for Problem 2 has higher within cell utilization than the two-cell solution, but has more inter-cell movement also. If parts can be rerouted or machines duplicated, the inter-cell movement can be reduced and the three-cell solution may be preferable. If part rerouting or machine duplication is expensive, or inter-cell movement will cause significant problems, the two-cell solution may be preferable. The same can be said for problem 6 . So it is important to have multiple solutions to choose from. Another advantage of the SCFA procedure is its simplicity. This is useful given that companies prefer simple cell formation procedures. Many of the other cell formation algorithms would be difficult for practitioners to comprehend. The SCFA procedure is also simple to set up using a spreadsheet package.

In summary, the effectiveness of the SCFA approach, along with its simplicity, and its low cost of use, make it useful for practising managers and researchers alike. Further research could involve using an expert system along with this procedure for analyses such as modifying part routings, duplicating machines or subcontracting. 


\begin{tabular}{|c|c|c|c|c|c|c|c|c|c|c|c|c|c|c|c|c|c|c|}
\hline & & & & \multicolumn{6}{|c|}{ SCFA } & \multicolumn{3}{|c|}{ SC-Seed } & \multicolumn{3}{|c|}{ HPH Method } & \multicolumn{3}{|c|}{ 0-1 Programming } \\
\hline $\begin{array}{l}\text { Prob- } \\
\text { lem }\end{array}$ & $\mathrm{N}$ & M & $\begin{array}{c}\text { Matrix } \\
\text { Dens- } \\
\text { ity }^{1} \\
\end{array}$ & $\begin{array}{l}\text { No. } \\
\text { of } \\
\text { cells }\end{array}$ & $e_{1}$ & $\mathrm{e}_{2}$ & e & c & b & e & c & $b$ & e & c & $b$ & e & c & $\mathrm{b}$ \\
\hline 1 & 10 & 15 & 0.31 & 3 & 0.92 & 0.0 & 0.92 & 2.06 & 1.41 & 0.93 & 2.13 & 1.37 & - & - & - & - & - & - \\
\hline \multirow[t]{2}{*}{2} & \multirow[t]{2}{*}{19} & \multirow[t]{2}{*}{12} & \multirow[t]{2}{*}{0.33} & 2 & 0.57 & 0.12 & 0.45 & 3.78 & 1.27 & - & - & - & - & - & - & - & - & - \\
\hline & & & & 3 & 0.64 & 0.28 & 0.36 & 3.78 & 1.29 & - & - & - & 0.37 & 4.69 & 1.29 & - & - & - \\
\hline 3 & 20 & 8 & 0.38 & 3 & 1 & 0.15 & 0.85 & 3.99 & 1.33 & 0.85 & 4.26 & 1.31 & 0.85 & 3.87 & 1.38 & - & - & - \\
\hline 4 & 43 & 16 & 0.18 & 5 & 0.64 & 0.24 & 0.40 & 6.74 & 1.17 & 0.45 & 8.24 & 1.02 & 0.42 & 8.44 & 1.11 & - & - & - \\
\hline 5 & 35 & 20 & 0.19 & 4 & 0.78 & 0.02 & 0.76 & 2.94 & 1.56 & 0.76 & 3.83 & 1.40 & - & - & - & - & - & - \\
\hline \multirow[t]{2}{*}{6} & \multirow[t]{2}{*}{20} & \multirow[t]{2}{*}{8} & \multirow[t]{2}{*}{0.57} & 1 & 0.57 & 0 & 0.57 & 5.16 & 1.33 & 0.57 & 6.20 & 1.21 & - & - & - & - & - & - \\
\hline & & & & 2 & 0.79 & 0.31 & 0.48 & 5.16 & 1.33 & - & - & - & - & - & - & - & - & - \\
\hline 7 & 41 & 30 & 0.11 & 5 & 0.52 & 0.15 & 0.37 & 23.4 & 1.10 & - & - & - & - & - & - & $0.16^{2}$ & 3.83 & 0.91 \\
\hline \multirow[t]{2}{*}{8} & \multirow[t]{2}{*}{24} & \multirow[t]{2}{*}{14} & \multirow[t]{2}{*}{0.18} & 2 & 0.33 & 0 & 0.33 & 3.01 & 1.24 & - & - & - & - & - & - & 0.33 & 2.91 & 1.08 \\
\hline & & & & 4 & 0.66 & 0.03 & 0.66 & 3.01 & 1.24 & - & - & - & - & - & - & 0.66 & 2.91 & 1.08 \\
\hline
\end{tabular}

NOTE: ${ }^{1}$ The matrix density is given by $\frac{\sum_{\mathrm{i}}^{\mathrm{M}} \sum_{\mathrm{j}}^{\mathrm{N}} a_{\mathrm{ij}}}{\mathrm{M} x N}$

where $a_{i j}=(0,1)$, one element in the part machine matrix.

${ }^{2}$ Two cell solution

Table 3

Numerical results of the comparative study 


\section{REFERENCES}

Wemmerlov, U., and Hyer, N.L., "Cellular manufacturing in the U.S. industry: a survey of users", International Journal of Production Research, Vol. 27, No. 9, 1989, pp.1511-1530.

Offodile, O.F., Mehrez, A., and Grznar, J., "Cellular manufacturing: a taxonomic review framework", Journal of Manufacturing Systems, Vol. 13, No. 3, 1994, pp.196-220.

Cheng, C.H., " Algorithms for grouping machine groups in group technology, OMEGA, Vol. 22, No. 4, 1992, pp. 493-501.

Askin, R.G., Cresswell, S.H., Goldberg, J.B., and Vakharia, A.J., "A hamiltonian path approach to reordering the part-machine matrix for cellular manufacturing.", International Journal of Production Research, Vol. 29, No. 6, 1991, pp.1081-1100.

King, J.R., and Nakornchai, V., "Machine-component group formation in group technology: review and extension", International Journal of Production Research, Vol. 20, No.1, 1982, pp.117-133..

Wei, J.C., and Gaither, N., "An optimal model for cell formation decisions", Decision Sciences, Vol. 21, No. 2, 1990, pp. 416-433.

Miltenburg, J., and Zhang, W., "A Comparative Evaluation of nine well-known algorithms for solving the cell formation problem in group technology", Journal of Operations Management, Vol. 10, No. 1, 1991, pp. 44-69.

Chandrasekharan, M.P., and Rajagopalan, R., "An ideal seed non-hierarchical clustering algorithm for cellular manufacturing",International Journal of Production Research, Vol. 24, No. 2, 1986a, pp.451-464.

Srinivasan, G., Narendran, T.T., and Mahadevan, B., "An assignment model for the part-families problem in group technology", International Journal of Production Research, Vol. 28, No.1, 1990, pp145-152.

Waghodekar, P.H., and Sahu S., "Machine-component cell formation", International Journal of Production Research, Vol. 22, No. 6, 1984, pp.937-948.

McAuley, J., "Machine grouping for efficient production", Production Engineer, February, 1972, pp. 53-57.

Carrie, A., "Numerical taxonomy applied to group technology and plant layout", International Journal of Production Research, Vol. 11, No. 4, 1973, pp. 399-416.

Mosier, C.T., "An experiment investigating the application of clustering procedures and similarity coefficients to the GT machine cell formation problem", International Journal of Production Research, Vol. 27, No. 10, 1989, pp. 1811-1835.

4 Buffa, E.S., Armour, G.C. and Vollmann, T.E., "Allocating facilities with CRAFT", Harvard Business Review, Vol. 42, 1964, pp. 136-158.

Kusiak, A.., and Heragu, S.S., " The Facility Layout Problem", European Journal of Operational Research, Vol. 29, 1987, pp.229-251.

McCormick, W.T. Jr., Schweitzer, P.J., and White, T.W., "Problem decomposition and data reorganization by a clustering technique", Operations Research, Vol. 20, No. 5, 1972, pp.993-1009.

Chan, H.M., and Milner D.A.., Direct clustering algorithm for group formation in cellular manufacture, Journal of Manufacturing Systems, Vol. 1, No. 1,1982, pp. 65-74. 
18 De Witte, J., The use of similarity coefficients in production flow analysis, International Journal of Production Research, Vol. 18, No. 4, 1980, pp. 503-514.

19 Burbidge, J.L., The Introduction of Group Technology, New York, John Wiley, 1975.

20 Chandrasekharan, M.P., and Rajagopalan R., MODROC: An extension of rank order clustering for group technology, International Journal of Production Research, Vol. 24, No. 5, 1986b, pp.12211233.

21 Kumar, K.R., and Vanelli A., Strategic subcontracting for efficient disaggregated manufacturing, International Journal of Production Research, Vol. 25, No. 12, 1987, pp.1715-1728.

22 King, J.R., Machine component groupings in production flow analysis: an approach using rank order clustering algorithm, International Journal of Production Research, Vol. 18, No. 2, 1980, pp.213232. 
Appendix 1

Cells Created by SCFA

\begin{tabular}{|c|c|c|c|c|c|c|}
\hline \multirow{2}{*}{\multicolumn{2}{|c|}{ PROBLEM }} & \multicolumn{5}{|c|}{ CELL } \\
\hline & & 1 & 2 & 3 & 4 & 5 \\
\hline \multirow[t]{2}{*}{1} & Parts & 852 & 9634 & 1710 & & \\
\hline & Machines & 8531513 & 414961 & 72101112 & & \\
\hline \multirow[t]{4}{*}{2} & Parts & 1368132745 & $\begin{array}{l}10151416179 \\
11\end{array}$ & 191812 & & \\
\hline & Machines & 1211107 & 169842 & 35 & & \\
\hline & Parts & 1368132745 & $\begin{array}{l}14151016179 \\
11191812\end{array}$ & & & \\
\hline & Machines & 1211107 & 16984235 & & & \\
\hline \multirow[t]{2}{*}{3} & Parts & 71842063 & 10121515 & $\begin{array}{l}91711141319 \\
82216\end{array}$ & & \\
\hline & Machines & 2847 & 56 & 13 & & \\
\hline \multirow[t]{2}{*}{4} & Parts & $\begin{array}{l}22418104232 \\
403828372\end{array}$ & 30112724320 & $\begin{array}{l}12181592343 \\
19412133145 \\
29\end{array}$ & 13252631 & 363517346 \\
\hline & Machines & 11692 & 1211 & 865415 & 107 & 314 \\
\hline \multirow[t]{2}{*}{5} & Parts & $\begin{array}{l}34168141926 \\
22\end{array}$ & $\begin{array}{l}1224132277 \\
101831\end{array}$ & $\begin{array}{l}29175151323 \\
2520\end{array}$ & $\begin{array}{l}35322830911 \\
421633\end{array}$ & \\
\hline & Machines & 5610920 & 13414218 & 317871 & 1911161512 & \\
\hline \multirow[t]{2}{*}{6} & Parts & $\begin{array}{l}6111220758 \\
13171916\end{array}$ & $\begin{array}{lllll}21101514318 \\
94\end{array}$ & & & \\
\hline & Machines & 7356 & 8142 & & & \\
\hline \multirow[t]{2}{*}{7} & Parts & 43751718 & $\begin{array}{l}22011413339 \\
231232311040 \\
\end{array}$ & 2232113013 & $\begin{array}{l}24252815357 \\
829\end{array}$ & 1436341617 \\
\hline & Machines & 5151425 & $\begin{array}{l}11122122323 \\
1012\end{array}$ & 929192030 & 828274 & 1817267 \\
\hline \multirow[t]{4}{*}{8} & Parts & 1920172123 & 76188 & 243421 & $\begin{array}{l}1114221610 \\
12915513\end{array}$ & \\
\hline & Machines & 457 & 13121 & 101132 & 14986 & \\
\hline & Parts & $\begin{array}{l}19201721237 \\
618824\end{array}$ & $\begin{array}{l}3421111422 \\
16101291553 \\
\end{array}$ & & & \\
\hline & Machines & 45713121 & 10113214986 & & & \\
\hline
\end{tabular}




\section{Biographical Sketches}

DONALD KERR works for the Ford Motor Company in Oakville, Ontario, Canada. He holds a bachelor's degree in Mechanical Engineering from the University of Toronto and an MBA from the University of Western Ontario. In the past, he has worked for General Motors and has taught Operations Management at the University of Calgary. Mr. Kerr's interests include spreadsheet applications of Operations Management tools. He has presented papers in this area at conferences.

JAYDEEP BALAKRISHNAN is an associate professor of Operations Management in the Faculty of Management at the University of Calgary. He is currently a visiting scholar at the Chinese University of Hong Kong. He has a PhD from Indiana University and an MBA from the University of Georgia, both in Operations Management. His undergraduate degree is in Mechanical Engineering from Nagpur University in India. He has also worked for the automobile industry in India. Dr. Balakrishnan's research interests include facility layout and cellular manufacturing. He has published in various journals and presented papers at many international conferences. 